\title{
Analysis and Evaluation of Oil-water Relative Permeability Curves
}

\author{
Yang Manping*, Xi Wancheng, Zhao Xiaojing and Cheng Yanhong \\ Petroleum Department of Yanshan University, Qinhuangdao, Hebei, 066004, P.R. China
}

\begin{abstract}
Oil-water relative permeability curves are the characteristic curves of evaluating the oil-water infiltrating fluid and also are an important part of reservoir engineering studies. Through a large number of core flooding experiments, based on the establishment of oil-water relative permeability calculation models, the use of the function of the relative permeability curves divided these into the water phase concave, water phase convex and a water phase linear categories. The relationship between different types of relative permeability curves with reservoir characteristics, moisture content, common infiltration points, common permeation range and oil displacement efficiency have been evaluated. Analysis the distribution of the reservoir usable remaining oil and reservoir irreducible oil of different types of relative permeability curves.
\end{abstract}

Keywords: Curve classifications, distribution of irreducible oil, distribution of usable oil, oil-water relative permeability curves.

\section{INTRODUCTION}

Oil-water relative permeability curves are the basis for evaluation of oil-water two-phase flow capability and one of the most basic parametric curves in reservoir development, also are the indispensable data of reservoir engineering parameters calculating, dynamic data analysis, numerical simulation and so on [1-3]. At present, we have more research about oil and water relative permeability curves, but less research on different types of relative permeability curves and reservoir characteristics of remaining oil distribution relationships $[4,5]$. This study collected a total of 68 cores results of water displacing oil, based on the establishment of oil-water relative permeability calculation model [6] to classify the relative permeability curves. The relationship between different types of relative permeability curves with reservoir characteristics, common infiltration points, common permeation range, oil displacement efficiency and moisture content have been evaluated. Finally summarizes the reservoir usable remaining oil and reservoir irreducible oil of different types of relative permeability curves.

\section{CLASSIFICATION OF RELATIVE PERMEABIL- ITY CURVES}

As can be seen from the relative permeability curves morphological characteristics of the samples, the oil relative permeability $\left(\mathrm{K}_{\mathrm{ro}}\right)$ varies with water saturation $\left(\mathrm{S}_{\mathrm{w}}\right)$ are basically the same, and $\mathrm{K}_{\mathrm{ro}}\left(\mathrm{S}_{\mathrm{w}}\right)$ within the range of common permeation graphics are concave upward. The differences of oil-water relative permeability curves shape mainly in the aqueous phase relative permeability $\left(\mathrm{K}_{\mathrm{rw}}\right)$. Thus this use of the water phase relative permeability curves concave and convx [7] to divide the types of relative permeability curves were divided into aqueous phase concave, aqueous convex phase and aqueous phase linear (or water phase transition) three types.

\subsection{The Aqueous Phase Concave}

When there is a constant $\mathrm{K}_{\mathrm{rw}}\left(\mathrm{S}_{\mathrm{w}}\right)>0$ in the common permeation range, then graphics of $\mathrm{K}_{\mathrm{rw}}\left(\mathrm{S}_{\mathrm{w}}\right)$ within the range of permeation is concave upward, to the types of curves called aqueous phase concave. There are 21 cores in the 68 samples belong to that type, representing $30.88 \%$ of the total samples, and the typical curve shape shown in Fig. (1). As can be seen from Fig. (1), the oil phase relative permeability curves were faster in the early steep decline, with the water saturation increases, the decline speed gradually slowed in the latter. The aqueous phase relative permeability curves at the beginning of a more moderate rate of increase, with the increase of the water saturation gradually accelerated in the latter part, final aqueous phase permeability values is relatively high.

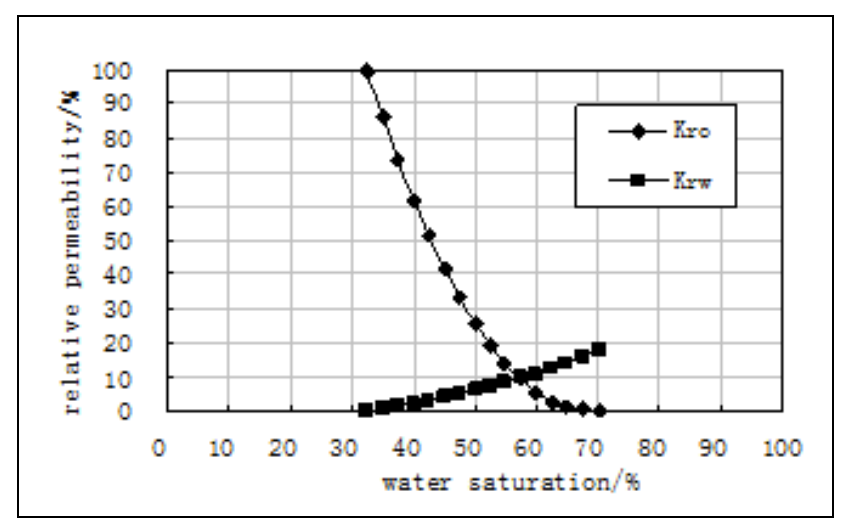

Fig. (1). The typical characteristics of aqueous phase concave relative permeability curves. 


\subsection{The Aqueous Phase Convex}

When there is a constant $\mathrm{K}_{\mathrm{rw}}\left(\mathrm{S}_{\mathrm{w}}\right)<0$ in the common permeation range, then graphics of $\mathrm{K}_{\mathrm{rw}}\left(\mathrm{S}_{\mathrm{w}}\right)$ within the range of permeation is convex upward, to the types of curves called aqueous phase convex. There are 23 cores in the study samples belong to that type, representing $33.83 \%$ of the total samples, and the typical curve shape shown in Fig. (2). As can be seen from Fig. (2), oil phase relative permeability curves similar with water phase, but decreasing magnitude faster than the water phase concave. The aqueous phase relative permeability curves at the beginning of faster rate of increase, with the increase of the water saturation gradually slowed in the latter part, final aqueous phase permeability values is relatively low.

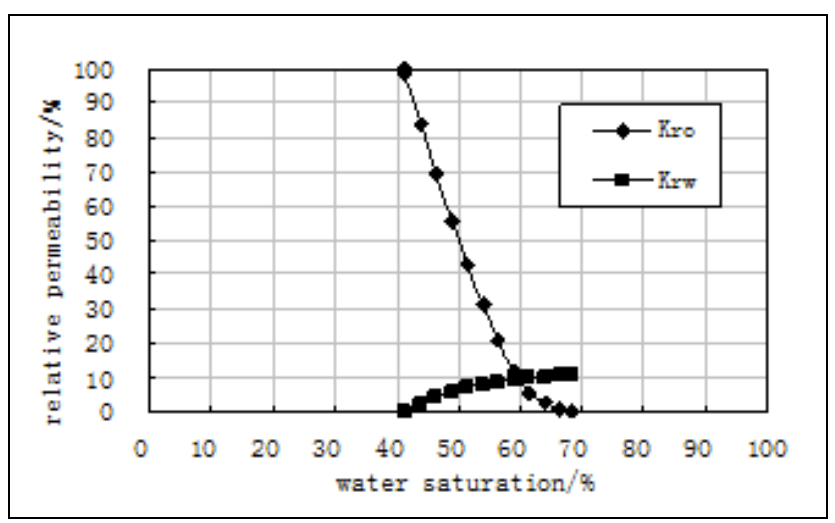

Fig. (2). The typical characteristics of aqueous phase convex relative permeability curves.

\subsection{The Aqueous Phase Linear (Transition Type)}

When there is a constant $\mathrm{K}_{\mathrm{rw}}{ }^{\prime}\left(\mathrm{S}_{\mathrm{w}}\right)=0$ in the common permeation range, then graphics of $\mathrm{K}_{\mathrm{rw}}\left(\mathrm{S}_{\mathrm{w}}\right)$ within the range of permeation is a straight line, to the types of curves called aqueous phase linear. There are 24 cores in the study samples belong to that type, representing $35.29 \%$ of the total samples, and the typical curve shape shown in Fig. (3). The aqueous phase linear is a transition type of the first two categories, the final values of aqueous phase relative permeability in between.

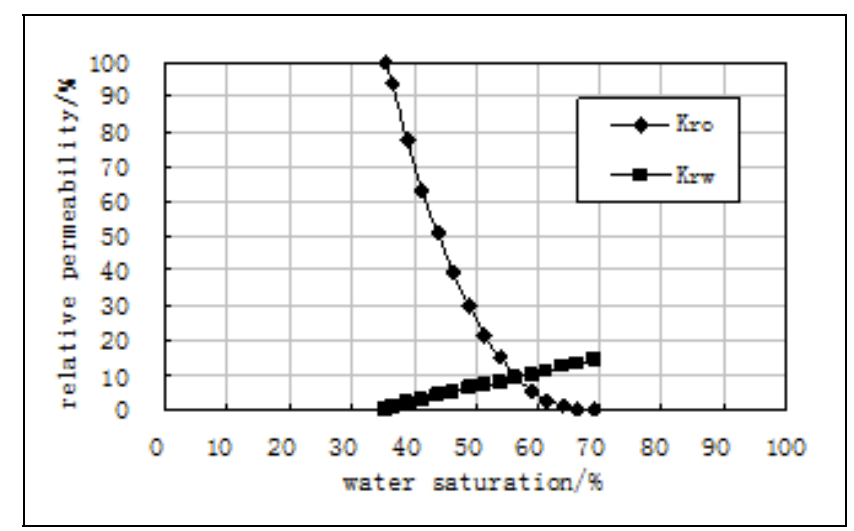

Fig. (3). The typical characteristics of aqueous phase linear relative permeability curves.

\section{EVAlUation OF RELATIVE PERMEABILITy CURVES}

\subsection{Reservoir Characteristics}

From the reservoir properties of different types of relative permeability curves (Table 1) can be seen: the porosity and permeability values of water phase concave, permeability values of oil phase and oil saturation is high, irreducible water saturation values lower. The aqueous phase convex and concave is opposite to aqueous phase, the aqueous phase between concave and convex aqueous phase of the parameters of the aqueous phase linear between reservoir properties. Overall, from the water phase concave, the aqueous phase linear to the aqueous phase convex reservoir properties gradually deteriorated.

Table 1. Reservoir characteristics of different relative permeability curves.

\begin{tabular}{|c|c|c|c|}
\hline $\begin{array}{c}\text { Reservoir } \\
\text { Characteristics }\end{array}$ & $\begin{array}{c}\text { Aqueous Phase } \\
\text { Concave }\end{array}$ & $\begin{array}{c}\text { Aqueous Phase } \\
\text { Linear }\end{array}$ & $\begin{array}{c}\text { Aqueous Phase } \\
\text { Convex }\end{array}$ \\
\hline \hline$\Phi / \%$ & 22.19 & 21.97 & 20.49 \\
\hline $\mathrm{K} / 10^{-3} \mu \mathrm{m}^{2}$ & 321.49 & 137.06 & 35.36 \\
\hline $\mathrm{K}_{\mathrm{ro}} / 10^{-3} \mu \mathrm{m}^{2}$ & 155.62 & 67.53 & 14.79 \\
\hline $\mathrm{S}_{\mathrm{w}} / \%$ & 31.95 & 39.08 & 43.08 \\
\hline $\mathrm{S}_{\mathrm{oi}} / \%$ & 68.05 & 60.92 & 56.92 \\
\hline
\end{tabular}

\subsection{Variation of Moisture Content}

From different types of relative permeability curves of moisture content and water saturation curve shows in Fig. (4): the water moisture of water phase concave relative permeability curves rise slower in the early water injection, with an increase in the moisture content of water injection rate began to rise greatly, and the rise amplitude of final moisture content gradually decreased again. Overall, the rate of increase in the moisture content of the type show a "slow fast - slow" mode, and the final amplitude is significantly slower than the previous. The moisture content of aqueous phase convex relative permeability curves rise faster in the initial development, with the increasing of injected water it gradually slows down, and the rise amplitude is the minimum in the end. Overall, it appears that the rate of increase in the moisture content of the type show a "fast - slow" mode. The water phase linear is a transitional mode of first two types, some of them close to the water phase concave, some close to the water phase convex, but the statistical results are more close to the former, accounting for $63.6 \%$ of the total number of samples.

\subsection{Common Infiltration Points, Common Permeation Range and Oil Displacement Efficiency}

(1) Three kinds of relative permeability curves of common infiltration points in accordance with the aqueous phase concave, the aqueous phase convex and an aqueous phase linear gradually move to the right. The relative permeability of common infiltration point mainly concentrated in $9 \%$ to $10 \%$, and less volatile. The water saturation of 
common infiltration point in more than $55 \%$, indicating that the reservoir has a water wettability. From the water phase concave to the aqueous phase linear and aqueous phase convex it gradually increases.

(2) The common permeation range of water phase concave, aqueous phase linear and aqueous phase convex gradually narrow. Combined with the characteristics of relative permeability curves, we can determine the final values of water phase concave relative permeability curves is maximum, generally between $18 \%$ to $20 \%$. The final values of water phase convex relative permeability curves are minimum, generally between $10 \%$ to $12 \%$. The final values of aqueous phase linear relative permeability curves are intermediate, generally between $12 \%$ to $18 \%$.

(3) From Table 2, the oil displacement efficiency of different relative permeability curves is not the same, the water phase concave relative permeability curves have the highest oil displacement efficiency, the high pore productivity, and the high water free recovery.

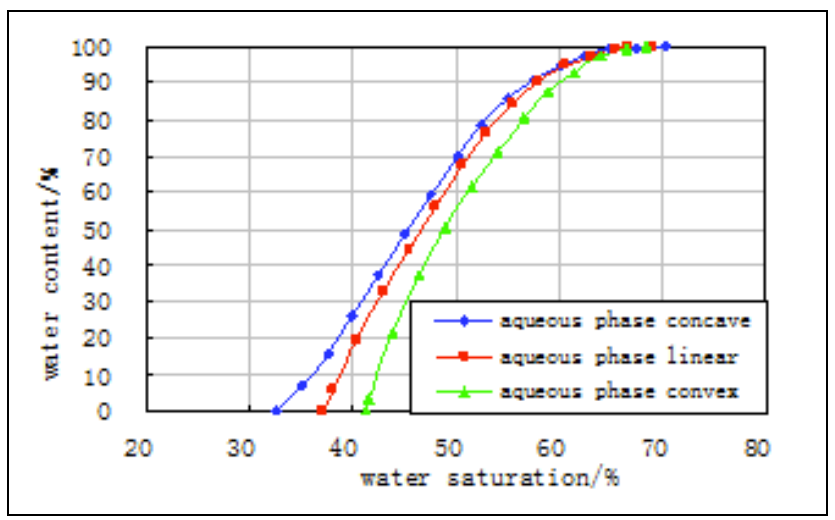

Fig. (4). Relation curve of water content and water saturation.

\section{THE CHARACTERISTICS OF RESERVOIR US- ABLE REMAINING OIL OF DIFFERENT RELATIVE PERMEABILITY CURVES}

\subsection{The Characteristics of Reservoir Usable Remaining Oil}

Water flooding reservoir usable remaining oil refers to the ratio of water flooding method can use the underground volume of oil and the ratio of the total pore volume, in value equal to the difference between the initial oil saturation and residual oil saturation. According to the classification of relative permeability curves, we analyze average of three samples relative permeability curves usable oil saturation. As can be seen from Fig. (5), the aqueous phase concave of the average usable oil saturation maximum to $38.21 \%$, the aqueous phase linear (transition) followed by $30.89 \%$ and the water phase convex lowest by $26.65 \%$. This shows that the reservoir which its relative permeability curves showed aqueous phase concave, the result of water flooding better, and water displacement efficiency or recovery higher.

\subsection{The Characteristics of Reservoir Usable Remaining Oil}

According to water flooding and relative permeability data, analyze the characteristics of reservoir usable remaining oil when the moisture content is $20 \%, 40 \%, 60 \%, 80 \%$ and $90 \%$, and study that distribution regular of different relative permeability curve types.

Table 3 and Fig. (6) for different types of relative permeability curves corresponding to different moisture content which related to the usable remaining oil distribution. As can be seen, the same moisture content, the usable remaining oil saturation of water phase concave highest, and the aqueous phase convex followed by aqueous phase linear. With the increase of moisture content, usable remaining oil saturation of all types relative permeability curves are also decreasing.

\section{THE CHARACTERISTICS OF RESERVOIR RE- SIDUAL OIL OF DIFFERENT RELATIVE PERME- ABILITY CURVES}

Irreducible oil refers to the remaining oil that can't be used under the condition of the current water flooding. The irreducible oil saturation of water flooding oil field refers to the ratio of the volume of remaining oil and the pore volume in the reservoir when the moisture content reaches to $100 \%$ [8]. The irreducible oil saturation is a relative value. With the progress of oil recovery technology, a part of the irreducible oil can be turned into remaining oil. For example, using chemical flooding can displace a part of the water flooding irreducible oil. There are many factors affecting the oil saturation of water flooding development, such as the pore structure of reservoir, the type of sedimentary microfacies and the type of relative permeability curve. We mainly research on the irreducible oil distribution in the reservoir with different types of relative permeability curve this time.

Table 2. Displacement efficiency comparison of different relative permeability curves.

\begin{tabular}{|c|c|c|c|}
\hline Relative Permeability Curves Parameters & Aqueous Phase Concave & Aqueous Phase Linear & Aqueous Phase Convex \\
\hline \hline Common infiltration points $/ \%$ & 56.92 & 59.87 & 61.28 \\
\hline Common permeation range $/ \%$ & 38.21 & 30.89 & 26.65 \\
\hline Displacement efficiency/\% & 56.09 & 26.38 & 22.52 \\
\hline Water free recovery/\% & 28.88 & 11.77 & 8.27 \\
\hline $\mathrm{K}_{\text {rw }}$ of irreducible oil/\% & 17.34 & 0.16 & 0.14 \\
\hline Pore productivity & 0.19 & 7.23 & 9.69 \\
\hline Distribution function of oil/water front & 5.81 & & \\
\hline
\end{tabular}




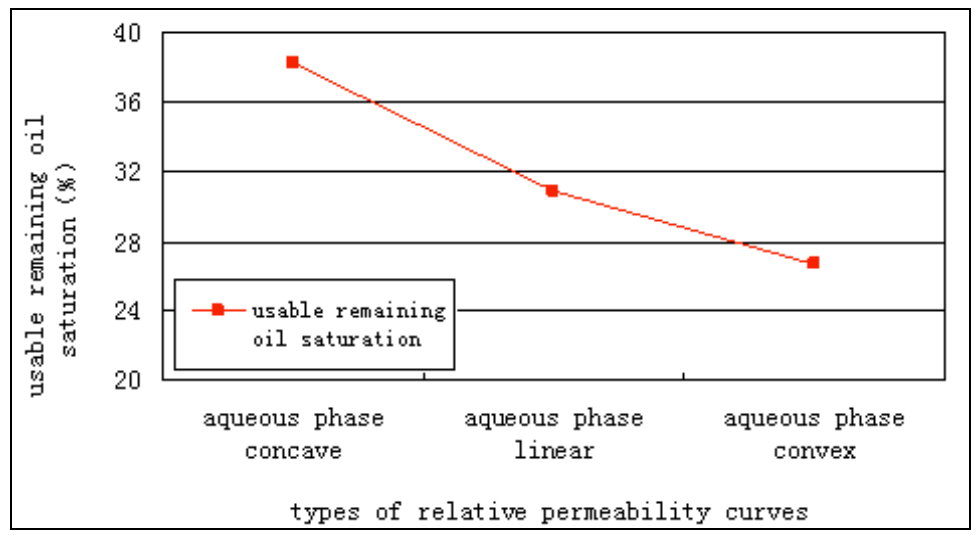

Fig. (5). Usable remaining oil characteristics of different relative permeability curves.

Table 3. Usable remaining oil saturation distribution of different relative permeability curves.

\begin{tabular}{|c|c|c|c|c|c|}
\hline $\begin{array}{ll}\text { Types of Curves } & \text { Water Content } \\
\end{array}$ & $20 \%$ & $40 \%$ & $60 \%$ & $80 \%$ & $90 \%$ \\
\hline Aqueous phase concave & 33.16 & 28.72 & 24.05 & 18.43 & 14.29 \\
\hline Aqueous phase linear & 27.52 & 23.85 & 19.98 & 15.14 & 11.61 \\
\hline Aqueous phase convex & 23.86 & 21.02 & 17.61 & 13.28 & 10.05 \\
\hline
\end{tabular}

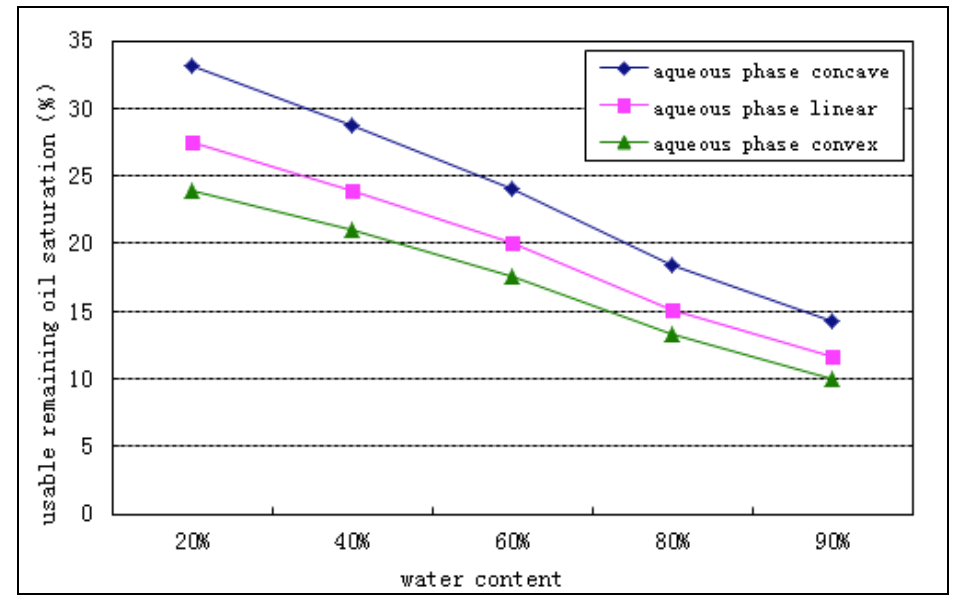

Fig. (6). Different water contents corresponding usable remaining oil saturation of different curves.

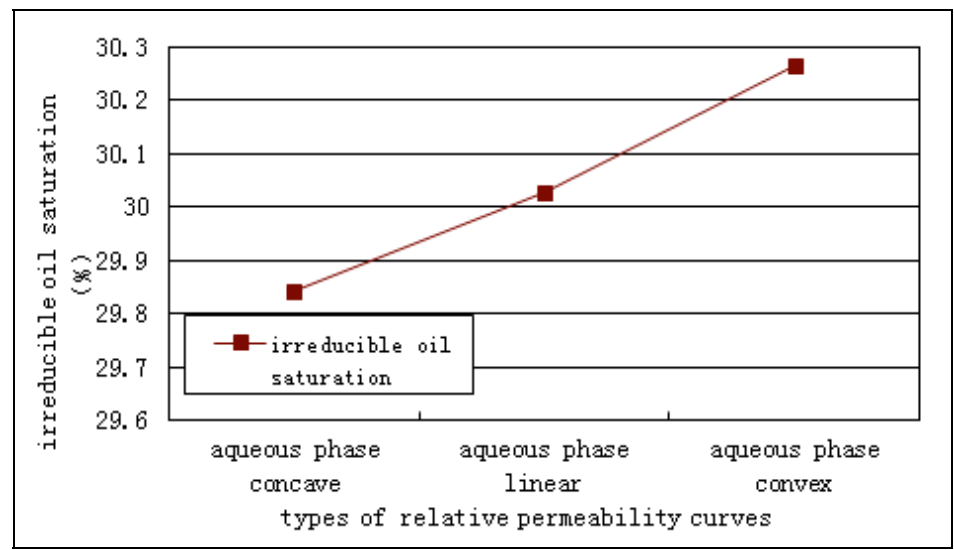

Fig. (7). Irreducible oil characteristics of different relative permeability curves. 
The value of the irreducible oil saturation is different in different types of relative permeability curve. The water flooding effect of the aqueous phase concave reservoir is good, and the value of the irreducible oil saturation is low, at $29.84 \%$. The water flooding effect of the aqueous phase linear (or water phase transition) reservoir takes second place, at $30.03 \%$. The water flooding effect of the aqueous convex phase reservoir is the worst, and the value of the irreducible oil saturation is also the highest, at $30.27 \%$ as shown in (Fig. 7).

\section{CONCLUSION}

(1) According to the curve shape of the relative permeability curves divided into the aqueous phase concave, convex and the aqueous phase linear three types. The aqueous phase concave has good reservoir properties, strong water wettability, big common permeation range, high oil displacement efficiency, high degree of water free recovery, the aqueous phase convex and concave opposite, and the aqueous phase linear between the two types.

(2) From the point of view throughout the displacement process, the rate of increase in the moisture content of aqueous phase concave show a "slow - fast - slow" mode, and the final amplitude is significantly slower than the previous. And the rate of increase in the moisture content of aqueous phase convex shows a "fast - slow" mode.

(3) From the characteristics of reservoir usable oil and residual oil, the water phase concave relative permeability curves these are the highest in these two properties, and the aqueous phase convex followed by aqueous phase linear.

\section{CONFLICT OF INTEREST}

The authors confirm that this article content has no conflict of interest.

\section{ACKNOWLEDGEMENTS}

Declared none.

\section{REFERENCES}

[1] J.Z. Xie, and X.L. Wu, "Estimation of oil water relative permeability curves from production logging data", Petroleum Exploration and Development, vol. 31, no. 2, pp. 64-66, 2004.

[2] X.W. Zhang, and J.H. Yin, "Features of oil water relative permeability curves for low permeability sandstone reservoir", Special Oil \& Gas Reservoirs, vol. 6, no. 2, pp. 27-31, 1999.

[3] X.D. Lv, W.G. Feng, Y. Yang, H.P. Li, and X.W. Zhang, "A new method of calculating relative permeability curve with performance data", Special Oil \& Gas Reservoirs, vol. 16, no. 5, pp. 65-66, 2009.

[4] W.Q. Zhao, "Analyses of Production Performance in an Oil Well Based on Oil-water Relative Permeability Curve", MS thesis, China University of Geosciences, Beijing, 2010.

[5] Q.T. Yu, "A method for treating oil-water relative permeability curves”, Xin Jiang Petroleum Geology, vol. 15, no. 4, pp. 361-364, 1994.

[6] S.G. Wang, G.Z. Zhao, and B.J Yu, "Statistical regularity of oilwater relative permeability in Daqing oil field", Acta Petrolei Sinica, vol. 26, no. 3, pp. 78-81, 2005 .

[7] Y.M. Chen, Higher Mathematics. BJ: Mechanical Industry Press, 2001, pp. 207-211.

[8] Y.T. Li, Principles and Methods of Enhanced Oil Recovery. BJ: Petroleum Industry Press, 2008, pp. 21-29.

Received: January 25, 2015

Revised: March 01, 2015

Accepted: March 10, 2015

(C) Manping et al.; Licensee Bentham Open.

This is an open access article licensed under the terms of the Creative Commons Attribution Non-Commercial License (http://creativecommons.org/licenses/by-nc/3.0/) which permits unrestricted, non-commercial use, distribution and reproduction in any medium, provided the work is properly cited. 